\title{
Left atrial perforation following device closure of atrial septal defect
}

\author{
*Janaki Keerthiwansa ${ }^{1}$, Nisansala Amarasinghe ${ }^{2}$, Chaminda Herath ${ }^{3}$, Sunethra Irugalbandara ${ }^{4}$, Kapila \\ Hettiarachchi $^{5}$, Mohomad Faizal ${ }^{6}$, Anil Abeywickrama ${ }^{7}$, Priyantha Dissanayake ${ }^{8}$ \\ http://dx.doi.org/10.4038/sljch.v49i3.9151 \\ Sri Lanka Journal of Child Health, 2020; 49(3): 290-291
}

(Key words: ASD device closure, cardiogenic shock, cardiac tamponade, pericardiocentesis)

\section{Introduction}

Isolated secundum atrial septal defects (ASDs) account for $7 \%$ of congenital heart defects ${ }^{1}$. Surgical or trans-catheter device closure is advised for all symptomatic patients and also for asymptomatic patients with a Qp: Qs ratio of at least 2:1 ${ }^{1}$. Atrial septal occlusion devices are implanted transvenously in the cardiac catheterization laboratory. The results are excellent and patients are discharged the following day.

\section{Case report}

A 10 year old girl was brought from the school with a history of sudden onset chest pain and faintishness. On admission to the local hospital, she was in cardiogenic shock. Five months ago she underwent device closure of ASD. After initial resuscitation with 2 normal saline boluses and dobutamine infusion, her ultrasound scan (USS) of the chest revealed a large pericardial effusion with an organized clot. She was then transferred to a paediatric cardiac tertiary care unit, which is located 45 minutes away, by an ambulance. On admission, patient was in cardiogenic shock due to cardiac tamponade of haemopericardium with a large thrombus. ASD device was well aligned without any residual leak or valvular dysfunction.

${ }^{1}$ Consultant Paediatrician, ${ }^{2}$ Senior House Officer in Paediatrics, ${ }^{3}$ Consultant Radiologist, District General Hospital), Nawalapitiya, ${ }^{4}$ Consultant Paediatric Cardiologist, $\quad{ }^{5}$ Consultant Anaesthesiologist, $\quad{ }^{6}$ Consultant Paediatric Intensivist, Sirimavo Bandaranayake Children's Hospital, Peradeniya, ${ }^{7}$ Consultant Paediatric Cardiothoracic Surgeon, ${ }^{8}$ Consultant Anaesthesiologist, Teaching Hospital Kandy

*Correspondence: janaki_kee@yahoo.com

orcid.org/ 0000-0001-9066-3083

(Received on 26 November 2018: Accepted after revision on 18 January 2019)

The authors declare that there are no conflicts of interest

Personal funding was used for the project.

Open Access Article published under the Creative

Commons Attribution CC-BY (c) (P)

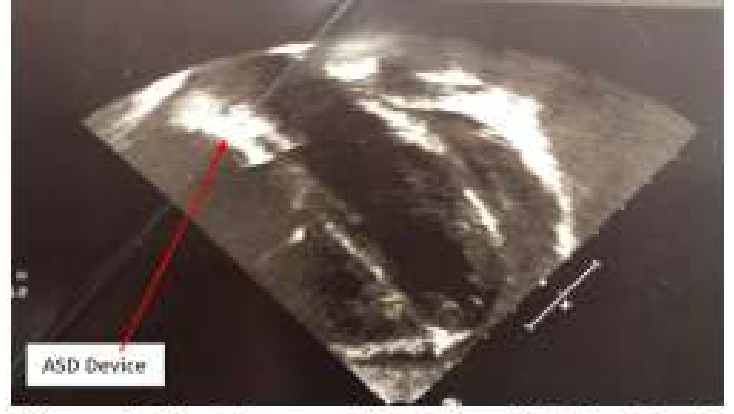

Figure 1: Size 16mm well positioned ASD device is visualized in echocardiogram

Emergency pericardiocentesis was done while transfusing blood and $300 \mathrm{ml}$ of blood was removed. Child was transferred to the paediatric intensive care unit (ICU) following insertion of a $6 \mathrm{~F}$ pig tail catheter. As again $90 \mathrm{ml}$ collection of blood was drained, child underwent emergency exploration. Right atriostomy was performed under cardiopulmonary by-pass with cardioplegic arrest. Altered blood with a large clot in the pericardial space was found.

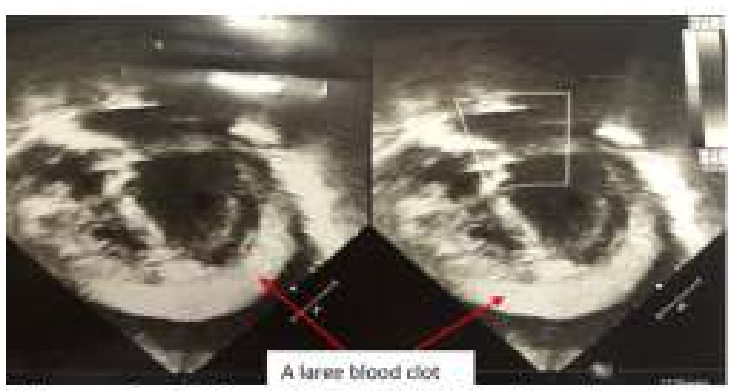

Figure 2: Echocardiogram showing large clot located in pericardial sac

Left atrial perforation due to erosion of the roof of the left atrium was found surrounded by a discoloured area. Epithelialized device was removed and a primary repair of the left atrial perforation and patch closure of the ASD were performed successfully. The post-operative period was uneventful and she was discharged 5 days after surgery. 


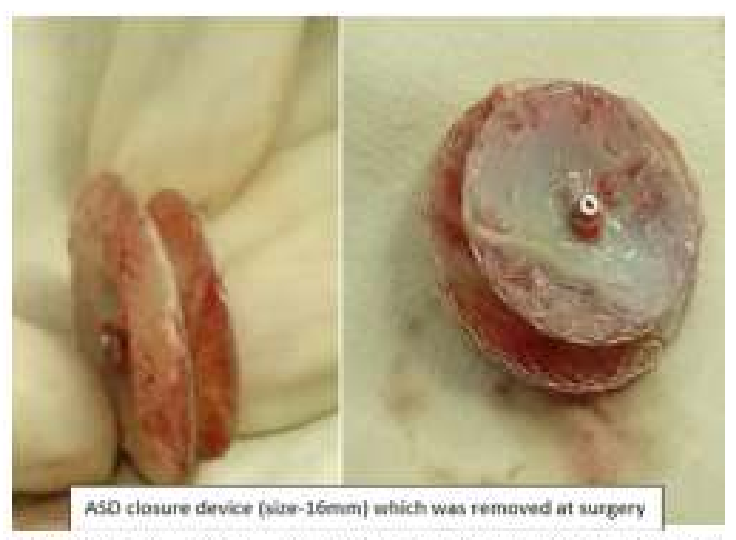

Figure 3: ASD closure device which caused erosion of left atrial wall causing cardiac tamponade

\section{Discussion}

ASD device closure is gaining popularity because of cosmetic benefits, reduced pain and reduced hospital stay $^{2}$. However, technical complications with occasional deaths have been reported $^{2}$. The complications reported include cardiac perforation, device malposition or embolisation, residual shunts, vascular trauma, thrombus formation, arrhythmia, infective endocarditis and sudden death ${ }^{2}$.

Malposition or embolisation is the commonest reason for surgical intervention ${ }^{2}$. Perforation is the next common complication ${ }^{2}$. Incidence varies from $0.1 \%$ to $4.0 \%$ for different devices ${ }^{3}$. The technique related cardiac perforation occurs during catheterization typically before hospital discharge and is amenable to intervention ${ }^{2}$. Device related perforations occur, mostly after hospital discharge and are potentially lethal ${ }^{3}$. Erosion events are most often ascribed to device mismatch due to over-sizing or deficient retro-aortic rims ${ }^{3}$. The antero-superior atrial wall and or adjacent aorta are uniquely vulnerable ${ }^{2}$. Perforation could occur even after 6 months ${ }^{2}$.

\section{References}

1. Daniel Bernstein. Nelson Text Book of Paediatrics. $20^{\text {th }}$ edition. Philadelphia: Elsevier; 2016.

2. Raghuram AR, Krishnan R, Kumar S, Balamurugan K. Complications in atrial septal defect device closure. Interactive Cardiovascular and Thoracic Surgery 2008; 7(1):167-9.

3. Crawford GB, Brindis RG, Krucoff MW, Mansalis BP, Carroll JD. Percutaneous atrial septal occlude devices and cardiac erosions: a review of the literature, Catheterisation and Cardiovascular Interventions 2012; 80(2):157-67. 